\title{
MEDIATING EFFECTS OF ENGLISH PROFICIENCY ON THE ASSOCIATION BETWEEN RELIGIOSITY COMMITMENT, STUDY HABITS, SELF-STUDY CONCEPT, AND PERCEIVED STRESS
}

Mohd Aidil Riduan Awang Kader ${ }^{*}$, Nurul Nadia Abd Aziz ${ }^{2}$, Mohamad Ridhuan Mat Dangi ${ }^{3}$

${ }^{1 *}$ Faculty of Business and Management, Universiti Teknologi MARA Pahang (Jengka Campus), Pahang, Malaysia; ${ }^{2}$ Faculty of Business and Management, Universiti Teknologi MARA Pahang (Raub Campus), Pahang, Malaysia; ${ }^{3} \mathrm{Faculty}$ of

Accountancy, Universiti Teknologi MARA Selangor, Puncak Alam Campus, Selangor, Malaysia.

Email: ${ }^{1 *}$ aidilriduan@uitm.edu.my, ${ }^{2}$ nurul_nadia@uitm.edu.my, ${ }^{3}$ ridhuan@uitm.edu.my

Article History: Received on $24^{\text {th }}$ July 2020, Revised on $15^{\text {th }}$ September 2020, Published on $26^{\text {th }}$ September 2020

\section{Abstract}

Purpose of the study: The purpose of this study is to examine the relationship between religiosity commitment, self-study concept, study habits, and English proficiency. Besides, this paper aims to investigate the way English proficiency mediates the relationship between religiosity commitment, self-study concept, and study habits with perceived stress, respectively, among undergraduates, enrolled in a Management course.

Methodology: A quantitative method was employed in this study involving 243 undergraduates of Universiti Teknologi MARA (UiTM) Pahang. The respondent selection method employed a simple random sampling technique. A questionnaire survey was designed based on previous literature. Statistical Package for Social Sciences (SPSS) 22.0 and Structural Equation Modelling (SEM) using AMOS software were used to analyze and test all hypotheses developed.

Main Findings: This study found a significant relationship between religiosity commitment, study habits, and self-study concept with English proficiency. The results also demonstrated a positive and significant relationship between English proficiency and perceived stress. Furthermore, the results of this study revealed that English proficiency mediated the relationship between religiosity commitment, study habits, self-study concept, and perceived stress.

Applications of this study: This study is intended to provide insight for undergraduates to identify the critical factors that can contribute to their English proficiency. Furthermore, it can serve as a guideline and control mechanism for the university and lecturers to ensure the course will be delivered excellently, which will lead to an increase in English proficiency and reduce the stress level among university students.

Novelty/Originality of this study: Due to the lack of research considering English proficiency as a mediator, this study will bridge the gap by examining the mediating role of English proficiency on the relationship between religiosity commitment, study habits, self-study concept, and perceived stress.

Keywords: English Proficiency, Perceived Stress, Religiosity Commitment, Self-study Concept, Study Habits.

\section{INTRODUCTION}

Being a university student is not as easy as expected and many challenges will be faced, including academic stress and mental health implications. This situation is reinforced by studying at universities that use English as a medium of instruction in the teaching and learning process. It requires high commitment from the student specifically to increase their English proficiency. If the teaching and learning process is not handled well, it can create stress among students, thus contributing to many negative impacts. Many kinds of research have been done to investigate the relationship between English proficiency and perceived stress among university students (Bai, 2016; Ennsa et al., 2018; Taušováa et al., 2019; Teng et al., 2020; Xing \& Bolden, 2019). On top of this, the transition experienced from the teaching and learning environment in high school to university level will contribute to perceived stress among university students, especially for first semester students. This was proven by Spivey et al. (in press), who found a relationship between years of study in a university and perceived stress. The result of the study also showed that higher perceived stress among university students would contribute to lower academic performance. Universiti Teknologi MARA (UiTM) is one of the universities in Malaysia that uses English as a medium of instruction in the teaching and learning process. This is important as it is the most widely spoken language in the world and graduate marketability is mostly dependant on the level of English proficiency on top of excellent academic results and cocurriculum excellence. For university students, it is imperative to become proficient in English since most reading and reference materials such as textbooks are written in English, which requires them to understand the language to facilitate their teaching and learning process more effectively. As a result, it is crucial for the students to enhance their English proficiency and be more competitive at the university level and soon throughout their careers. Although UiTM requires teaching and learning processes to be done fully in English, many students are unable to master English proficiency either written or verbally. Incompetence in this aspect can contribute to stress among students since all assignments, presentations, quizzes, tests, and final examinations are conducted in English. Therefore, students have to work harder to become an expert 
in English. Lack of conversational and writing skills, inadequate vocabulary knowledge, inability to complete assignments in English using self-written sentences rather than "copy and paste" and inadequacy of communicating with proper grammar are among the significant problems confronted by undergraduates (Afzal, 2019; Al Nakhalah, 2016; Mofareh, 2019; Rabea et al., 2018). The Fundamentals of Management (MGT162) is a compulsory course that needs to be taken by Diploma in Accountancy students at UiTM. Through the new syllabus, this course is offered to those enrolled in the Diploma in Accountancy, which has been previously taken by second-semester students. This course entails the students to understand the terms, definitions, and concepts of management, which is probably difficult to be translated into Malay and thus requires high English proficiency. According to the result released in March 2020, the failure rate for this course was 3.3\%. Even though the failure rate is relatively low and still under the Key Performance Indicator (KPI) of the university, the faculty is unable to sustain the $0 \%$ failure rate compared to previous semesters. Therefore, the faculty needs to investigate and identify the critical predictor factors that can contribute to English proficiency, which leads to reduce stress as university students and finally contribute to better academic performance.

University students also need to possess good internal factors to succeed in English, which includes self-study concept, study habits, and religiosity commitment. The self-study concept is related to students' initiative to manage their time efficiently for studying English, as well as other courses that mostly use English as a medium of instruction and thus able to schedule their time with classes, assignments, studying for quizzes, tests, and final examinations. They should actively participate during class and always discuss between their peers by using English as the medium of communication. Besides, students need to hold excellent study habits skills, including studying consistently, capable to eliminate distractions, focused, and giving full attention during class to improve their English proficiency. A majority of UiTM students are Muslim. Therefore, religiosity commitment is needed to adhere to the Islamic thought, which emphasizes discipline and continuous improvement for one's betterment. To some extent, all religions accentuate the concept of continually improving their adherents to do well in everything they do and continuously improve themselves. Therefore, the religiosity commitment is required in increasing the English proficiency among university students to reduce stress during the teaching and learning process in a university environment, which will lead towards achieving better academic performance.

Unfortunately, there is a lack of research considering English proficiency as a mediator to see the relationship between the above-mentioned constructs with perceived stress. This means that the relationship between religiosity commitment, study habits, and self-study concept with perceived stress can be more complex and may consist of intermediate interactions, such as the mediating effects, and thus deserve further investigation. Hence, the objective of this study is: 1) to examine the internal factors including religiosity commitment, self-study concept, and study habits towards English proficiency and 2) to investigate the way English proficiency mediates the relationship between religiosity commitment, self-study concept, and study habits with perceived stress among undergraduates in Management course. The implication of this study is to provide insight for the undergraduates, particularly for first semester students, to identify the essential factors that can contribute to their English proficiency for them to prepare, cope, and adapt to the new environment. This is due to the teaching and learning process at the university level being different from the high school level. Furthermore, it can provide a guideline and control mechanism especially for the faculty, management, and lecturers regarding the teaching and learning process to ensure the course will be delivered excellently. Therefore, it will lead to increased English proficiency and reduced stress level among university students.

\section{LITERATURE REVIEW}

\section{Religiosity Commitment and English Proficiency}

Religiosity commitment is associated with internal quality wherein students should have it to reflect the degree in which one complies with the religious thoughts in their life. This includes praying, reading the Quran for Muslims, being honest, hardworking, and always doing well in everything they do to be a better man. Many past studies have investigated the relationship between religiosity commitment and English proficiency. Khodadady and Saadi (2015) examined the relationship between religiosity commitment and English proficiency in 216 university students in Iran. The result of the study revealed no significant relationship between religious commitment and English proficiency. The result of this study is also congruent with Moosavi (2014), who did not find any significant correlation between spiritual commitment and students' English language achievement. This means that English proficiency does not relate to the students' religious commitment. However, the study from Horwitz et al. (2020) found a positive association between religiosity commitment and English language achievement. They revealed that students with higher religious commitment pursued better grades in the English language. The result of the study is congruent with the study by Ramlee et al. (2016), who examined 320 undergraduates from Malaysia public higher education institutions and exposed that religiosity has a positive relationship towards academic excellence including the English language. Based on the above literature, it is postulated that:

H1: There is a significant relationship between religiosity commitment and English proficiency. 


\section{Study Habits and English Proficiency}

Study habits related with students' behavior and strategy used to acquire knowledge among university students include the frequency of student involved in studying session, revision on learning materials, taking notes on important content, selfassessment, being punctual with their attendance, and practicing the past year examination questions in advance to ease their study process (Alos et al., 2015; Amri et al., 2019; Jafari et al., 2019; Kumar et al., 2017; Sabbah, 2016). Dian (2018) investigated the relationship between students' study habits and English proficiency by using smartphone in Indonesia. The result exposed that a majority of the respondents claimed that the method of using a smartphone could increase English proficiency, especially their listening skills. Sabbah (2016) also examined the impact of study habits on English Language achievement in Qatar and found a significant association between study habits and English proficiency. Besides, research by Kumar et al. (2017) also proved that study habits such as reading and note-taking, course and final exam preparation, and focus behaviors would lead to English proficiency. Alos et al. (2015) also did a study on 74 fourth-year nursing students in the Philippines and discovered that study habits had a positive influence on academic performance. On top of that, Amri et al. (2019) also found a positive correlation between study habits and English learning achievement among students in Indonesia. The result of their study concluded that the better the students' study habits, the higher their English proficiency. The results of the above studies are consistent with the study by Ndifon et al. (2014), which examined the study habits and students' English language academic performance in Nigeria. They exposed that study habits such as group reading, individual reading, and note-taking habits had a significant relationship with students' English language performance. Therefore, it is hypothesized that:

\section{H2: There is a significant relationship between study habits and English proficiency.}

\section{Self-study Concept and English proficiency}

Self-study involves engaging students in individual revision, group discussions, and providing additional learning materials to enhance their language skills. This concept is crucial for university students to equip themselves with English proficiency. Many scholars had investigated the relationship between the self-study concept and English proficiency (Bai et al., 2020; Sun \& Wang, 2020; Teng et al., 2020; Truong \& Wang, 2019; Zhang et al., 2020). Bai et al. (2020) examined 291 students in Hong Kong to measure the association of self-regulated learning writing strategies including planning, self-initiation, textgenerating, self-monitoring, and revising towards English writing proficiency. The result proved a positive association between the self-study concept in writing strategy and English writing proficiency. This result is also congruent with the study by Teng et al. (2020), who investigated 389 undergraduates in China by using the mix-method approach and found a significant correlation between self-learning strategy and English writing proficiency. From the interview method, many respondents claimed that they had a strong willingness to read English articles and practice English writing to improve their English proficiency. Besides, Truong and Wang (2019) also revealed a relationship between self-efficacy and English proficiency among 767 college students in Vietnam. In terms of English speaking skills, Zhang et al. (2020) used mixedmethod to analyze the positive association between self-study concepts, including English speech performance among 82 undergraduates in China. The result of this study exposed a positive correlation between the two constructs measured. This meant that the more they practiced, the better their English speech performance. Therefore, according to the above literature, it is postulated that:

\section{H3: There is a significant relationship between self-study concept and English proficiency.}

\section{English Proficiency and Perceived Stress}

University students typically will have perceived stress due to unhealthy competition. Many students obsess on getting a high-Grade Point Average (GPA), which can lead to stress since low academic performance may have an impact on their future. This is in terms of rejection for opportunities such as scholarships and peers' acceptance, and ultimately may affect their job offers. Many research works have been done to investigate the relationship between English proficiency and perceived stress among university students. A study by Teng et al. (2020) towards 389 Chinese graduates found that high English proficiency would have a low impact on emotional control or stress. The result of this study is consistent with Ennsa et al. (2018), who examined 203 university students majoring in psychology, nursing, and social work in the United States. They discovered that higher emotional intelligence, including English proficiency, was associated with lower perceived stress. A study by Muliawati et al. (2020) also exposed moderate anxiety levels among students sitting for the English TOEFL examination since they were well-prepared. Besides, Xing and Bolden (2019) investigated the relationship between English learning motivation in Chinese international students and English proficiency. They revealed that undergraduates perceived high levels of stress at university due to their low oral English proficiency. The above results are also congruent with the study by Taušováa et al. (2019), who researched 319 international students from 62 countries in the Netherlands. The result showed that English proficiency had a negative correlation with mental health problems, as well as perceived stress. Bai (2016) also examined the relationship between English proficiency and perceived stress concerning 1355 international students in the United States Midwestern University. However, the result revealed no significant relationship 
between English proficiency and perceived stress since the entry requirement for English proficiency was very high at this university for international students. Therefore, there were no problems for international students to excel in English. Therefore, based on the above literature, it is hypothesized that:

H4: There is a significant relationship between English proficiency and perceived stress.

\section{English Proficiency as Mediator}

Many past studies had shown that the direct relationship between religiosity commitment (Abdel-Khaled \& Lester, 2017; Achour et al., 2017; Miller et al., 2012; Thomas et al., 2016; Zawawi, 2015), study habits (Dhanalakshmi \& Murty, 2017; Rao \& Ready, 2015), self-study concept (Abdel-Khaled \& Lester, 2017; Huh, 2015) and perceived stress. For example, Achour et al. (2017) investigated the association between religiosity commitment and level of stress among 230 Muslim undergraduates in Malaysian universities. The results revealed a statistically significant relationship between religious commitment and level of stress, which means the higher religiosity commitment, the lower their level of stress. Besides, Miller et al. (2012) also found a negative association between religiosity commitment and perceived stress. The higher religious commitment of the university students will contribute to the lower depression level. Zawawi (2015) also investigated the correlation between religiosity and perceived stress among 209 undergraduates in Jordan. He discovered that students with higher levels of religious involvement would have the propensity to forgive others and have a lower stress level. However, the above findings contradict Thomas et al. (2016), who demonstrated the lack of association between religiosity and depressive symptoms amongst female citizens of the United Arab Emirates. Besides, Abdel-Khaled and Lester (2017) examined 702 of Muslim Arab college students in Kuwait and revealed no significant relationship between religiosity commitment and level of stress.

Dhanalakshmi and Murty (2017) did a study on the effect of study habits and perceived stress among 300 students in India. They found that the proper study habits of the students could reduce the level of their stress. The result of this is also similar to the research by Rao and Ready (2015), who exposed that a lack of study habits by the students will lead to higher perceived stress. Furthermore, the result also revealed that the perceived stress was higher for first-year students compared to second-year students since they lacked good study habits due to the lack of teaching and learning experience in a university environment. Abdel-Khaled and Lester (2017) also found the significant negative relationship between self-efficacy and level of stress, which means the more the students use self-study concepts, the lower their level of stress in coping with their studies. A study by Huh (2015) explored the mediator role of English proficiency. The study aimed to investigate the differences in the perceived stress from learning English and the academic self-concept in South Korea. The finding indicated that students' self-concept decreased according to years of studies and their learning stress-induced English proficiency had an insignificant impact on their self-study concept. In other words, English proficiency did not mediate the relationship between study self-concepts and perceived stress.

However, there is a lack of research considering English proficiency as a mediator to see the relationship between the abovementioned construct towards perceived stress. This means that the relationships between religiosity commitment, study habits, self-study concept, and perceived stress can be more complex and may consist of intermediate interactions such as the mediating effects, thus deserving further investigation. Due to that reason, the second objective of this study aims to investigate English proficiency mediates the relationship between religiosity commitment, study habits, self-study concept, and perceived stress especially in the context of undergraduates' in the Management course. Therefore, it is postulated that:

H5: English proficiency mediates the relationship between religiosity commitment and perceived stress.

H6: English proficiency mediates the relationship between study habits and perceived stress.

H7: English proficiency mediates the relationship between study self-concept and perceived stress.

Therefore, based on the above literature, the conceptual framework for this study is illustrated in Figure 1.

This study proposes a conceptual framework for a specific model designed to explain the link between religiosity commitment, study habits, self-study concept, and English proficiency with perceived stress. The current research lays out a conceptual framework designed to analyze the influence of religiosity commitment, study habits, and self-study concept on English proficiency, as well as the influence of English proficiency on perceived stress. This study also proposes English proficiency as a mediator variable. Figure 1 depicts the essential constructs included in this study, which will serve as a guide for subsequent discussions. In consideration of the literature review, the current research suggests that English proficiency will influence the path relationship between religiosity commitment, study habits, self-study concept, and perceived stress among university students. In summary, the theoretical framework in Figure 1 illustrates several hypotheses to be tested in the study. Hypotheses H1, H2, H3, and H4 are testing for causal effects. Meanwhile, other hypotheses H5, H6, and $\mathrm{H} 7$ are intended to test the mediation effects in the model. 


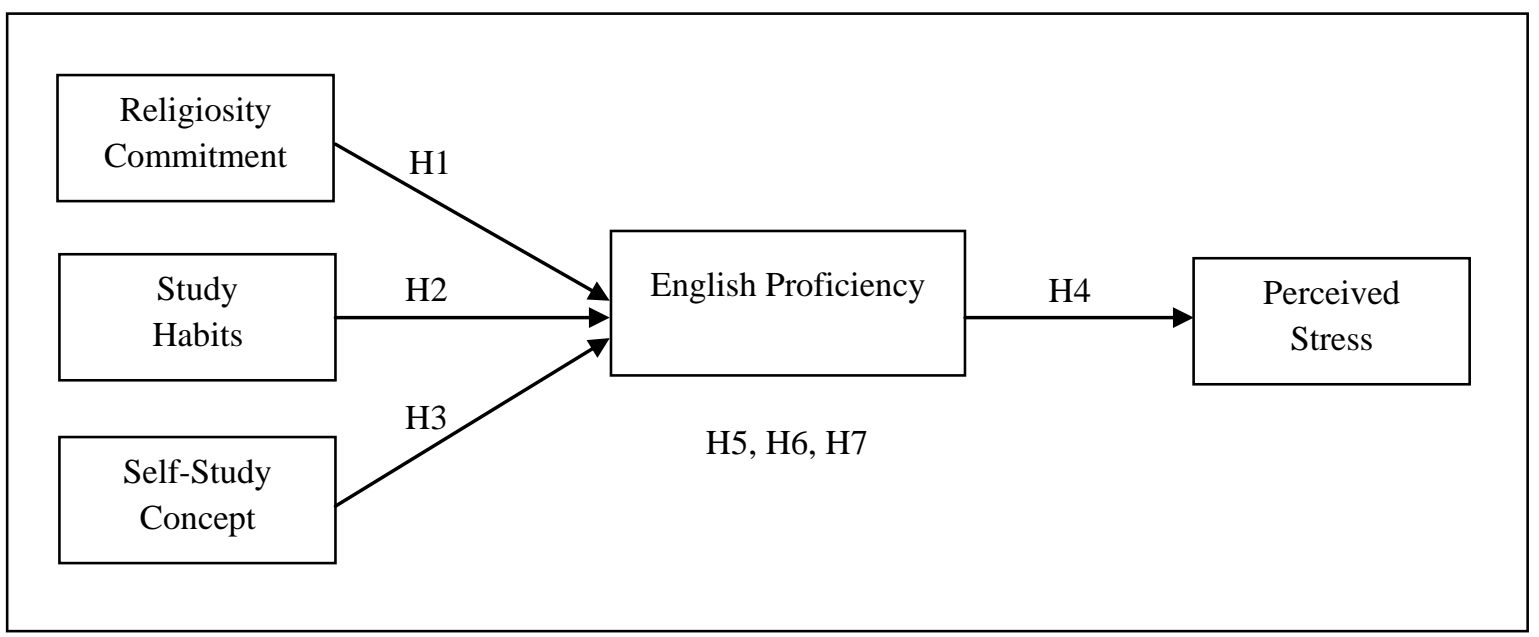

Figure 1: Theoretical Framework

\section{METHODOLOGY}

This section outlines the research design and approaches to accomplish the research objectives. A total of 243 respondents of Diploma in Accountancy students from UiTM Pahang, Jengka Campus were involved in this study. The respondent selection method used a simple random sampling technique. A questionnaire survey was designed based on previous literature and used as the research instrument in this study. The questionnaire was divided into two parts, A and B. Part A was intended to acquire the demographic information of the respondents. Part B was designed to measure the predicting factors that contribute to perceived stress, which included religiosity commitment, study habits, self-study concept, and English proficiency. The questionnaire used a 5-point Likert scale ranging from 1 (Strongly Disagree) to 5 (Strongly Agree). For each statement, respondents were required to indicate their level of agreement with the statements. The input for the statements was derived from Alos et al. (2015), Amri et al. (2019), Khodadady and Saadi (2015), Ramlee et al. (2015), and Thomas et al. (2016). Table 1 below shows the five constructs and the corresponding items used for each construct.

Table 1: The constructs and the corresponding questions

\begin{tabular}{|c|c|}
\hline Constructs & Corresponding questions \\
\hline Perceived Stress & $\begin{array}{l}\text { Time shortage to do the assignment. } \\
\text { Competition creates stress among us, academic students. } \\
\text { The complexity of work that makes me unable to understand it in a little time. } \\
\text { My academic stress at the beginning and middle semester goes from low to high and } \\
\text { affects my academic performance. } \\
\text { Increasing strictness and pressure from parents. }\end{array}$ \\
\hline English proficiency & $\begin{array}{l}\text { Easily to understand the presented books, but facing difficulty in expressing things in } \\
\text { my own words (reverse). } \\
\text { I am usually discussing the course material in my first language with friends (reverse). } \\
\text { I understand some things, but there is a lot that I miss or cannot comprehend (reverse). } \\
\text { I am struggling for using a proper English language because my language is still not } \\
\text { good enough for university-level (reverse). } \\
\text { Difficulty in expressing thoughts in spoken English (reverse). }\end{array}$ \\
\hline $\begin{array}{l}\text { Religiosity } \\
\text { Commitment }\end{array}$ & $\begin{array}{l}\text { I am always reciting Al-Quran. } \\
\text { I need to spend time in prayer. } \\
\text { I try hard to live all my life according to my religious beliefs. } \\
\text { I need to tell/speak the truth. } \\
\text { My religion is important because it answers many questions about the meaning of life. }\end{array}$ \\
\hline Study Habits & $\begin{array}{l}\text { I study only when there is a quiz or test (reverse). } \\
\text { I feel tired, bored, and sleepy in class (reverse). } \\
\text { I study only when I like (reverse). } \\
\text { I am disturbed when studying (reverse). } \\
\text { I am always preparing before I go to class. }\end{array}$ \\
\hline Self-Study Concept & I participate in class discussions. \\
\hline
\end{tabular}


I feel comfortable in a large class group.

I feel comfortable speaking in front of the class.

I make efficient use of time.

I am confident I can master skills-competency.

The survey data was analyzed using the Statistical Package for Social Sciences (SPSS) version 22.0 and Structural Equation Modelling (SEM) using the AMOS (Analysis of Moment Structures) software. The analysis is comprised of four main parts. Firstly, the summarization of the demographic profile of the respondents was analyzed. Secondly, confirmatory factor analysis (CFA) was conducted to determine the adequacy of model fit to the data. Thirdly, SEM-AMOS was employed to estimate complex causal-effect relationship models with latent variables. Lastly, the path analysis was conducted to assess the effect of English proficiency in mediating the relationship between religiosity commitment, study habits, and self-study concept on perceived stress.

\section{RESULTS}

\section{Analysis of Descriptive}

Table 2: Respondents' Profile

\begin{tabular}{|c|c|c|c|c|c|}
\hline & Frequency & $\%$ & & Frequency & $\%$ \\
\hline Gender & & & SPM Result - English & & \\
\hline Male & 74 & 30.5 & $\mathrm{~A}$ & 79 & 32.5 \\
\hline \multirow[t]{2}{*}{ Female } & 169 & 69.5 & $\mathrm{~B}$ & 163 & 67.1 \\
\hline & & & $\mathrm{C}$ & 1 & 0.4 \\
\hline \multicolumn{6}{|l|}{ Religion } \\
\hline \multirow[t]{2}{*}{ Islam } & 243 & 100.0 & SPM Result - History & & \\
\hline & & & $\mathrm{A}$ & 178 & 73.3 \\
\hline Age & & & $\mathrm{B}$ & 54 & 22.2 \\
\hline $18--21$ years old & 242 & 99.6 & $\mathrm{C}$ & 9 & 3.7 \\
\hline \multirow[t]{2}{*}{$22-25$ years old } & 1 & 0.4 & $\mathrm{D}$ & 1 & 0.4 \\
\hline & & & $\mathrm{E}$ & 1 & 0.4 \\
\hline \multicolumn{6}{|l|}{ School } \\
\hline Urban area & 173 & 71.2 & SPM - Islamic Education Result & & \\
\hline \multirow[t]{2}{*}{ Rural area } & 70 & 28.8 & A & 200 & 82.3 \\
\hline & & & $\mathrm{B}$ & 40 & 16.5 \\
\hline Secondary School Stream & & & $\mathrm{C}$ & 3 & 1.2 \\
\hline Social Science & 164 & 67.5 & & & \\
\hline Science and Technology & 48 & 19.8 & & & \\
\hline Religious & 31 & 12.8 & & & \\
\hline
\end{tabular}

This study employed IBM SPSS Statistics for data analyses. All socio-demographic data were analyzed descriptively and presented as frequencies as well as percentages. Two hundred and forty-three respondents participated in this study. From 243 respondents, 30.5 percent were males and 69.5 percent were females. The respondent age ranged from 18 to 25 years old. All respondents were Malay and Muslim. A total of 173 respondents ( 71.2 percent) received secondary education in urban areas, while the rest (28.8 percent) attended secondary school in rural areas. For the secondary school stream, 164 respondents (67.5 percent) pursued studies in social science, 48 respondents (19.8 percent) in science and technology, and 31 respondents (12.8 percent) were of the religious fields of study. This indicates that a majority of the respondents had basic knowledge in the Management course since they had learned a few subjects related to Management courses, such as Entrepreneurial Studies, Commerce, Principal of Accounting, and Economics. This basic knowledge is essential for students to understand the lessons more efficiently and effectively. Analysis of the Sijil Pelajaran Malaysia (SPM) or the Malaysian Certificate of Education examination results for English subjects also found that most respondents (67.1 percent) had grade $\mathrm{B}, 79$ respondents ( 32.5 percent) had grade $\mathrm{A}$, and only one student had grade $\mathrm{C}$. The results revealed that the majority of the respondents had medium-level English proficiency. Hence, they need more practice to improve English proficiency, especially when studying at UiTM that uses English as a medium of instruction. The results of the SPM examination for History and Religious Education subjects indicated that the majority of students obtained Grade A with 178 respondents (73.3 percent) and 200 respondents ( 82.3 percent), respectively. This demonstrates that most of the respondents possess high memorization power that can be used to memorize and understand the terms and facts, which will lead to reduced stress to study in the Management course. 
Table 3: The Assessment of Normality Distribution for Items in the respective construct

\begin{tabular}{ccccccc}
\hline Variable & min & max & skew & c.r. & kurtosis & c.r. \\
\hline PS1 & 1.000 & 5.000 & .125 & .798 & -.394 & -1.252 \\
\hline PS2 & 2.000 & 5.000 & -.031 & -.197 & -.741 & -2.358 \\
\hline PS3 & 1.000 & 5.000 & -.151 & -.959 & -.174 & -.552 \\
\hline PS4 & 1.000 & 5.000 & -.008 & -.052 & -.317 & -1.007 \\
\hline PS5 & 1.000 & 4.000 & .197 & 1.252 & -.845 & -2.689 \\
\hline ELC1 & 1.000 & 5.000 & -.241 & -1.534 & -.339 & -1.078 \\
\hline ELC2 & 2.000 & 5.000 & -.309 & -1.967 & .034 & .108 \\
\hline ELC3 & 1.000 & 5.000 & -.250 & -1.594 & -.120 & -.380 \\
\hline ELC4 & 1.000 & 5.000 & -.376 & -2.391 & -.089 & -.284 \\
\hline ELC5 & 1.000 & 5.000 & -.183 & -1.162 & -.304 & -.968 \\
\hline RC1 & 2.000 & 5.000 & .204 & 1.295 & -.510 & -1.622 \\
\hline RC2 & 3.000 & 5.000 & -.797 & -5.073 & -.509 & -1.620 \\
\hline RC3 & 1.000 & 5.000 & -1.093 & -6.957 & 1.705 & 5.425 \\
\hline RC4 & 2.000 & 5.000 & -.589 & -3.747 & -.664 & -2.112 \\
\hline SH1 & 1.000 & 5.000 & -.123 & -.784 & -.077 & -.245 \\
\hline SH2 & 1.000 & 5.000 & .034 & .217 & .106 & .337 \\
\hline SH3 & 1.000 & 5.000 & -.029 & -.185 & -.544 & -1.731 \\
\hline SH5 & 1.000 & 5.000 & .476 & 3.031 & .609 & 1.937 \\
\hline SS1 & 2.000 & 5.000 & -.159 & -1.011 & -.234 & -.744 \\
\hline SS2 & 1.000 & 5.000 & -.293 & -1.866 & -.111 & -.354 \\
\hline SS3 & 1.000 & 5.000 & -.138 & -.881 & .075 & .238 \\
\hline SS4 & 1.000 & 5.000 & .064 & .404 & .508 & 1.616 \\
\hline SS5 & 2.000 & 5.000 & .071 & .450 & -.195 & -.621 \\
\hline Multivariate & & & & & 62.980 & 14.475 \\
\hline & & & & & & \\
\hline & & & & & \\
\hline & & & & \\
\hline
\end{tabular}

The test of normality was employed to test the data distribution of the variables. In this study, the normality of data in terms of the skewness and kurtosis was examined by AMOS Version 25.0, as shown in Table 3. As these values were within the recommended guidelines of \pm 1.5 for skewness and kurtosis, respectively, univariate normality in the data was assumed.

\section{Confirmatory Factor Analysis}

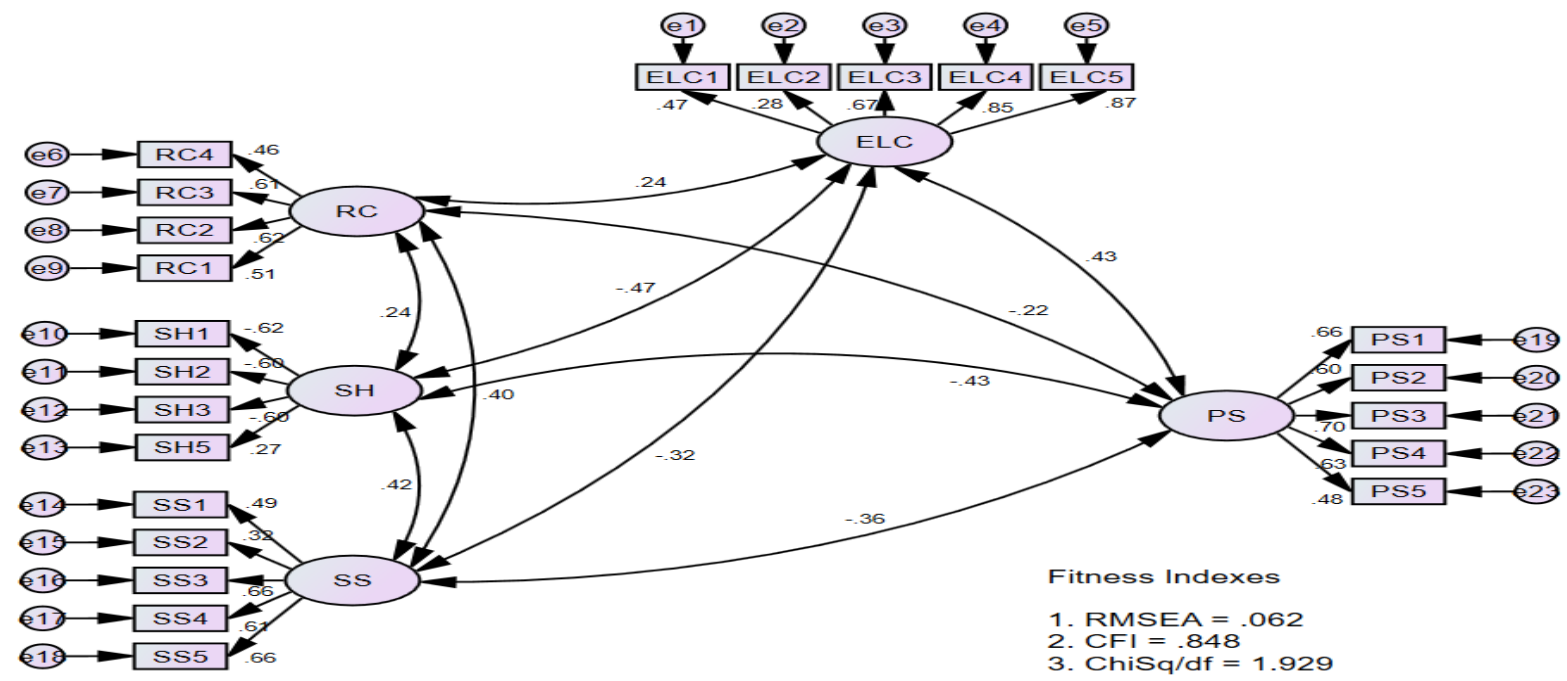

Figure 2: The CFA Results

Note $; \mathrm{N}=243 ; \mathrm{RC}=$ Religiosity Commitment; SH = Study Habits; SS = Self-Study Concept; ELC = English Proficiency; PS $=$ Perceived Stress. 
Table 4: Goodness-of-fit indices

\begin{tabular}{lll}
\hline Name of Category & Goodness-of-fit Measures & Index Value \\
\hline Absolute fit & RMSEA & 0.062 \\
\hline Incremental fit & CFI & 0.848 \\
\hline Parsimonious fit & ChiSq/df & 1.929 \\
\hline
\end{tabular}

Confirmatory factor analysis (CFA) was conducted to determine the goodness of fit of the model. Table 3 indicates that the goodness-of-fit indices of the proposed model of perceived stress fit the data reasonably well as confirmed by the RMSEA = .062 ; CFI $=.848$; and ChiSq/df $=1.929$. These fit index values suggest that the model is fit and can be used for further analysis. Figure 2 and Table 4 show the CFA results of the 23-items, five-factor scale.

\section{Structural Equation Modelling}

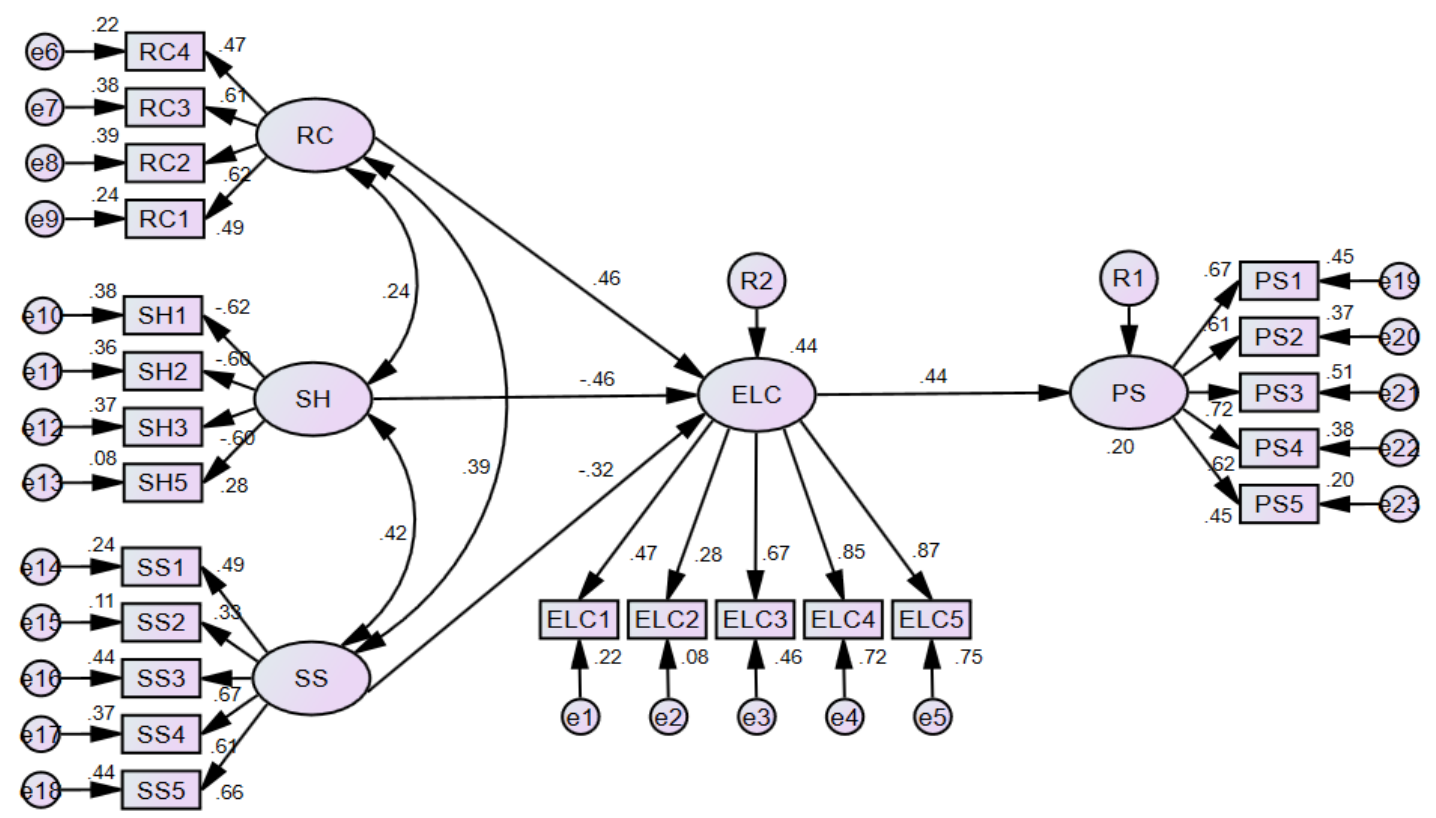

Figure 3: The Standardised Path Coefficients (Direct Relationship)

Note $; \mathrm{N}=243 ; \mathrm{RC}=$ Religiosity Commitment; SH = Study Habits; SS = Self-Study Concept; ELC = English Proficiency; PS $=$ Perceived Stress.

Table 5: The Regression Path Coefficients and Its Significance

\begin{tabular}{lllllll}
\hline & & Estimate & SE. & CR. & Results & Hypotheses \\
\hline H1 ELC $<---$ & RC & $.485^{* * *}$ & .134 & 3.614 & Significant & Supported \\
\hline H2 ELC $<---$ & SS & $-.291 *$ & .099 & -2.947 & Significant & Supported \\
\hline H3 ELC $<---$ & SH & $-.899^{*}$ & .322 & -2.790 & Significant & Supported \\
\hline H4 PS $<---$ & ELC & $.628 * * *$ & .140 & 4.488 & Significant & Supported \\
\hline
\end{tabular}

Notes: $\mathrm{N}=243$; $*$ Significant at the $\mathrm{p}<0.05, * * *$ Significant at the $\mathrm{p}<0.001, \mathrm{RC}=$ Religiosity Commitment; $\mathrm{SH}=\mathrm{Study}$ Habits; SS = Self-Study Concept; ELC = English Proficiency; PS = Perceived Stress.

Figure 3 illustrates that there is no multicollinearity problem as all the correlation values between the exogenous constructs were less than 0.85 . Figure 3 and Table 5 show the four hypotheses paths and regression weight for all four exogenous constructs towards the endogenous construct. The results indicated that the effect of the religiosity commitment, study habits, and self-study concept on English proficiency were all significant with $\beta=0.485, p<0.001, \beta=-0.291, p<0.05$, and $\beta=-$ $0.899, \mathrm{p}<0.001$, respectively. Also, the effect of English proficiency on perceived stress was significantly positive with $\beta=0.628, \mathrm{p}<0.001$. The results showed that all four hypotheses proposed $(\mathrm{H} 1, \mathrm{H} 2, \mathrm{H} 3$, and $\mathrm{H} 4)$ were supported. 


\section{Mediation Test}

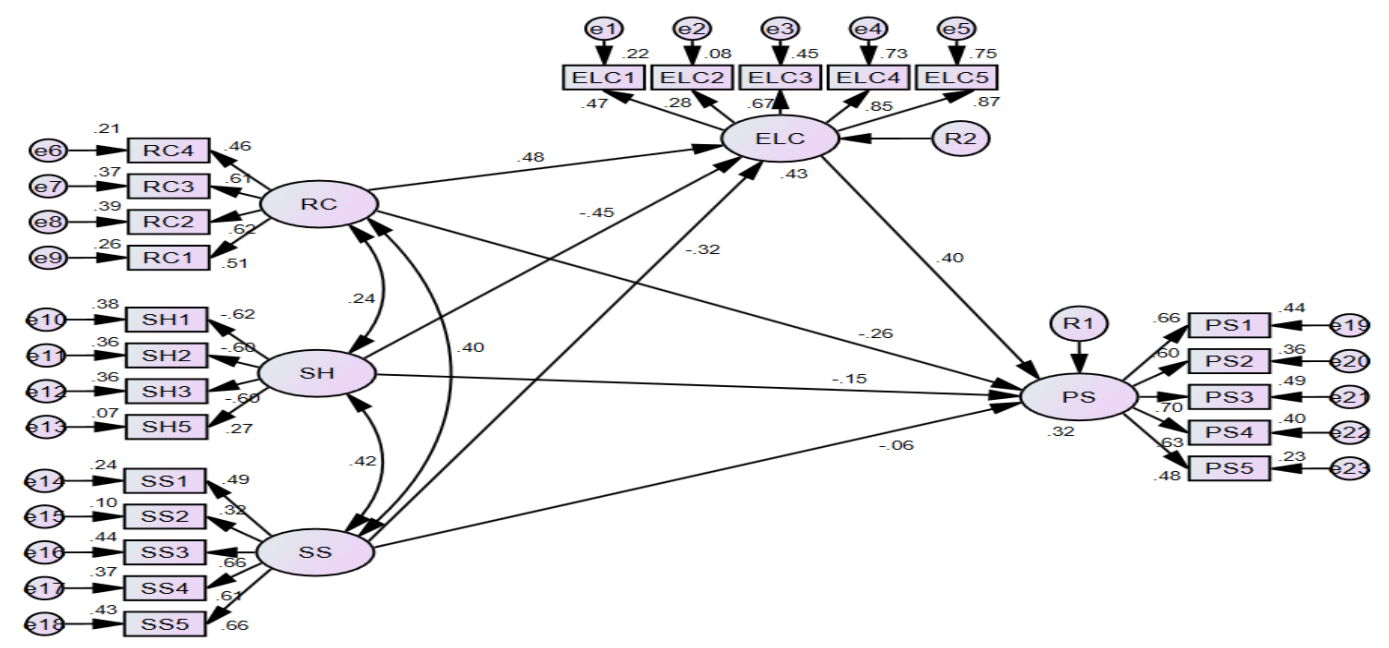

Figure 4: The Standardised Path Coefficients (Indirect Relationship)

Note $; \mathrm{N}=243 ; \mathrm{RC}=$ Religiosity Commitment; SH = Study Habits; SS = Self-Study Concept; ELC = English Proficiency; PS $=$ Perceived Stress.

Table 6: Testing English proficiency as a mediator in the relationship between RC and PS

\begin{tabular}{llll}
\hline & Estimate & P-value & Results \\
\hline (a) $\mathrm{RC} \rightarrow$ ELC & .677 & .000 & Significant \\
\hline (b) ELC $\rightarrow$ PS & .568 & .002 & Significant \\
\hline (c) $\mathrm{RC} \rightarrow$ PS & .360 & .047 & Significant \\
\hline (a) $\mathrm{x}(\mathrm{b})$ & .385 & Partial mediation since the direct effect is also significant \\
\cline { 1 - 2 } (a) $\mathrm{x}(\mathrm{b})>$ (c) & Mediation occurs & & \\
\hline
\end{tabular}

Note $; \mathrm{N}=243 ; \mathrm{RC}=$ Religiosity Commitment $; \mathrm{ELC}=$ English Proficiency; PS = Perceived Stress.

The results of the hypothesis tested in Figure 4 and Table 6 indicate that English proficiency does mediate the relationship between religiosity commitment and perceived stress. Thus, the type of mediation here was partial mediation since the direct effect was also significant after the mediator entered the model. Hence, the result indicated that H5 was supported.

Table 7: Testing English proficiency as a mediator in the relationship between SH and PS

\begin{tabular}{llll}
\hline & Estimate & P-value & Results \\
\hline (a) $\mathrm{SH} \rightarrow$ ELC & .906 & .006 & Significant \\
\hline (b) ELC $\rightarrow$ PS & .568 & .002 & Significant \\
\hline (c) $\mathrm{SH} \rightarrow$ PS & .433 & .224 & Not Significant \\
\cline { 1 - 2 } (a) $\mathrm{x}$ (b) & .515 & Full mediation since the direct effect is not significant \\
\cline { 1 - 2 } (a) $\mathrm{x}(\mathrm{b})>$ (c) & Mediation occurs & & \\
\hline
\end{tabular}

Note; $\mathrm{N}=243 ; \mathrm{SH}=$ Study Habits; ELC = English Proficiency; PS = Perceived Stress.

The results of the hypothesis tested in Figure 4 and Table 7 indicate that English proficiency does mediate the relationship between study habits and perceived stress. Thus, the type of mediation here was full mediation since the direct effect was no longer significant after the mediator entered the model. Hence, the result indicated that H6 is supported.

Table 8: Testing English proficiency as a mediator in the relationship between SS and PS

\begin{tabular}{llll}
\hline & Estimate & P-value & Results \\
\hline (a) SS $\rightarrow$ ELC & .290 & .004 & Significant \\
\hline (b) ELC $\rightarrow$ PS & .568 & .002 & Significant \\
\hline (c) SS $\rightarrow$ PS & .081 & .571 & Not Significant \\
\hline (a) $x($ b) & .165 & Full mediation since the direct effect is not significant \\
\cline { 1 - 2 } (a) $\mathrm{x}(\mathrm{b})>$ (c) & Mediation occurs & & \\
\hline
\end{tabular}


Note $; \mathrm{N}=243 ; \mathrm{SS}=$ Self-Study Concept ELC = English Proficiency; PS = Perceived Stress.

The results of the hypothesis tested in Figure 4 and Table 8 indicated that English proficiency mediated the relationship between self-study concept and perceived stress. Thus, the type of mediation here was full mediation since the direct effect was no longer significant after the mediator entered the model. Hence, the result indicated that $\mathrm{H} 7$ was supported.

\section{DISCUSSION AND CONCLUSION}

This study justified the influence of religiosity commitment, study habits, and self-study concept towards English proficiency among undergraduates by using structural equation modeling (SEM) technique to test the hypotheses. The results of this study indicated that religiosity commitment contributed positively to English proficiency. Thus, the results implied that students who were highly committed to religious thoughts would be more likely to achieve better English proficiency. This is aligned with the doctrine of all religions that educates its adherents to strive for success, including knowledge. Religiosity commitment caused UiTM Pahang students to work harder to improve their English proficiency, which enabled them to follow the teaching and learning process effectively since this university uses English as a medium of instruction. This will lead to better academic performance, especially in the Management course. This finding is in line with past studies that have found a positive relationship between religiosity commitment and English proficiency (Horwitz et al., 2020; Ramlee et al., 2016) and thus contributed to an increase in academic performance (Fenton-Smith et al., 2018; Umaru \& Sakariyau, 2016).

Contrary to the initial expectations, this study found a negatively significant relationship between study habits and English proficiency $(\beta=-0.291, p<0.05)$, as well as between self-study concept and English proficiency $(\beta=-0.899, p<0.001)$. In the present research, neither study habits nor self-study concept was positively related to English proficiency. Instead, study habits and self-study concept appeared to have more of a negative influence than a positive influence on English proficiency, indicating that the better the study habits and self-study concept one has, the lower their English proficiency. These findings contradict those described in previous research works (Alos et al., 2015; Amri et al., 2019; Bai et al., 2020; Dian, 2018; Kim \& Kim, 2014; Kumar et al., 2017; Ndifon et al., 2014; Sabbah, 2016; Sandilos et al., 2020; Teng et al., 2020; Truong \& Wang, 2019; Zhang et al., 2020) that show the positive relationship between study habits, self-study concept, and English proficiency. These contradictory results may be due to several reasons.

Firstly, becoming proficient in English not only requires good study habits and self-study concept, but it also requires the students to work in groups, actively participate in classroom activities and discussions, and make presentations (Aini et al., 2020; Dzulkurnain et al., 2020). This is parallel with the syllabus in the Management course, which entails the students to do a lot of group discussion and presentation assignments during class to build up their confidence level and improve English proficiency. Besides, the students must equip themselves with these managerial skills as they have the potential to be a manager or an accountant in the future.

Secondly, the personality traits of respondents may also contribute to the significant negative relationship between study habits and self-study concept towards English proficiency. This is in line with the study by Zabihi (2011), who confirmed that openness to experience, and friendliness could contribute to better English language performance. A majority of Accounting students in UiTM Pahang Jengka Campus are introverts; they are shy, quiet and prefer to spend time alone rather than being with other people compared to students from other faculties, namely the Faculty of Sport Science and Recreation who are more energetic and extroverted. Hence, it will make the teaching and learning process more difficult since this Management course requires students to work in groups, be involved in discussions, and make presentations as these tasks are not favored by people with introverted personalities.

A study by Aini et al. (2020) revealed that group discussion methods provided higher motivation to students in learning English reading comprehension compared to the self-study concept. Furthermore, classroom activity (Dzulkurnain et al., 2020) and remediation class (Luoch, 2014) are crucial to making students spend their attractiveness and full attention in learning English. Besides, the finding of this study is also congruent with the study by Inayah et al. (2020), who found that the motivation to learn outside the classroom became low due to many distractions such as social media applications. The result of the study by Vattoy and Smith (2019) also confirmed that teachers' feedback was more useful in studying English as a foreign language compared to self-study. McGrath et al. (2016) found that self-efficacy failed to increase English proficiency among university students since they lacked experience in reading English literature.

Furthermore, the results of the present study found a positive and significant relationship between English proficiency and perceived stress. These data contradict with those of previous researchers (Ennsa et al., 2018; Muliawati et al., 2020; Taušováa et al., 2019; Teng et al., 2020; Xing \& Bolden, 2019). A potential reason for the conflicting findings between the current study and prior scholars could be due to the time taken to adapt to the new teaching and learning environment since all respondents were first-semester students. The semester system commonly applied in university is different from the secondary school education system, which requires students to complete their assignments, quizzes, tests, and final examination within four months. Hence, students who are unable to adapt to this new environment will perceive stress 
although they are proficient in English. According to the English SPM examination result, a majority of the respondents obtained grade A and B, which indicated that they were good in English proficiency and qualified them to enroll in the Diploma in Accountancy in UiTM. Consequently, it is not surprising that the result of this study indicates the positive and significant relationship between English proficiency and perceived stress. Although they have excellent language skills, their stress is also high due to the inability to adapt to the new environment. This is parallel with the study by Rao and Ready (2015), who found that lack of experience in a university environment would lead to higher stress, particularly for first-year students.

Another possible reason for the contradictory finding is the different learning styles during secondary school and university. University level requires students not just to memorize but also to apply and involve critical thinking when answering examination questions and doing their assignments. Therefore, it would lead to stress since the respondents were not familiar with the new nature of learning style. This is in conjunction with the study by Bakar et al. (2017), who found that the different ways of learning between Diploma and Degree-level for Accounting students would contribute to the stress.

As an extension of the English proficiency study, the role of English proficiency was explored in mediating the relationship between religiosity commitment, study habits, and self-study concept and perceived stress. The study provides evidence to support the idea that English proficiency is an essential construct to understand the determining factors that may influence stress among undergraduates. The structural equation modeling analysis showed that English proficiency played a mediator role in the relationship between religiosity commitment, study habits, self-study concept, and perceived stress, respectively. The results suggested that a direct relationship in past research works (Alos et al., 2015; Amri et al., 2019; Bai et al., 2020; Dian, 2018; Horwitz et al., 2020; Kumar et al., 2017; Ndifon et al., 2014; Ramlee et al., 2016; Sabbah, 2016; Teng et al., 2020; Truong \& Wang, 2019; Zhang et al., 2020) was insufficient in illustrating the interactions of these constructs.

The presence of empirical evidence shows that the inclusion of English proficiency in the model will reduce the association between religiosity commitment, study habits, self-study concept, and perceived stress. Note that the indirect effect of religiosity commitment, study habits, and self-study concept on perceived stress via English proficiency $(\beta=0.385, \beta=0.515$, $\beta=0.165$ ) were higher than the direct effect of religiosity commitment, study habits, and self-study concept on perceived stress $(\beta=0.360, \beta=0.433, \beta=0.081)$. Specifically, English proficiency was found to partially mediate the relationship between religiosity commitment and perceived stress. Besides, English proficiency was also found to fully mediate the relationship between study habits and perceived stress, as well as that between self-study concept and perceived stress. Hence, instead of its role as direct antecedents to perceived stress, religiosity commitment, study habits, and self-study concept had an indirect influence on perceived stress through English proficiency as well, which this demonstrated a mediator effect.

The research findings in this study thus provided further empirical evidence to support and validate the role of English proficiency as a mediator in the relationship between religiosity commitment, study habits, and self-study concept on perceived stress which is discovered in previous research works. In other words, this study provided implications to the undergraduates by clarifying the impacts of religiosity commitment, study habits, self-study concept, and English proficiency as the contributors to perceived stress. The empirical findings in this study suggest that to reduce stress, students have to start by improving their religiosity commitment, study habits, and self-study concept. This is consistent with previous studies (Carter, 2016; Forouhari et al., 2019; Tekke et al., 2018). Supplementary to the direct impact on perceived stress, an improvement of religiosity commitment, study habits, and self-study concept was found to reduce the level of stress indirectly through the improved English proficiency. Consequently, undergraduates are urged to pay more attention to the aspect of managing and improving religiosity commitment, study habits, and self-study concept. In addition to that, the improvement of English proficiency can help undergraduates to reduce their stress.

\section{LIMITATION}

This study has several limitations. First, the respondents were only confined to the Diploma in Accountancy students of UiTM Pahang Jengka Campus. Therefore, the results of this study cannot be generalized as the Management course is also being undertaken by other Accounting students at other UiTM campuses. Second, this study was achieved using the simple random sampling technique for the respondent selection method rather than systematic random sampling since the convenience method might lead to sampling bias.

\section{FUTURE RESEARCH}

The present results of this study contradicted with findings described in previous research works that showed the positive relationship between study habits, self-study concept, and English proficiency. However, those studies did not exclusively focus on the joint impact of religiosity commitment, study habits, and self-study concept. This warrants further examination. Besides, in the present research, neither study habits nor self-study concept was positively related to English proficiency. Instead, study habits and self-study concept appeared to have more of a negative influence than a positive influence on English proficiency, indicating that the better the study habits and self-study concept one had, the lower their English 
proficiency. These findings contradict with findings described in previous research works. Therefore, future researchers may consider the role of personality traits as a moderator between study habits and English proficiency, as well as between selfstudy concept and English proficiency. This is due to becoming proficient in English not only requires good study habits and self-study concept, but it also requires the students to work in groups, be involved in discussions, and make presentations. The results of this study found a positive and significant relationship between English proficiency and perceived stress, which was inconsistent with the previous researchers. A potential reason for the conflicting findings between the current study and prior scholars could be due to the students' characteristics and would need further investigations. Since the lack of studies on the mediating effects of English proficiency on the association between religiosity commitment, study habits, selfstudy concept, and perceived stress could be noted, hence the replication of this study to other samples would be a productive subject for further research. As such, the present study provided the foundation for future exploration.

\section{ACKNOWLEDGEMENT}

This study was funded by the Department of Research, Industrial Network and Alumni, Universiti Teknologi MARA Pahang.

\section{AUTHORS' CONTRIBUTION}

Mohd Aidil Riduan Awang Kader wrote the research paper, refined the literature review and discussions of this paper, and was involved in paper submission. Nurul Nadia Abd Aziz wrote the research paper, refined the data analysis, and designed the organization of the study. Mohamad Ridhuan Mat Dangi wrote the literature review and involved in data analysis. All authors provided financial expenses equally for this research.

\section{REFERENCES}

1. Abdel-Khalek, A.M. \& Lester, D. (2017). The association between religiosity, generalized self-efficacy, mental health, and happiness in Arab college students, Personality and Individual Differences, 109, 12-16. https://doi.org/10.1016/j.paid.2016.12.010

2. Achour, M., Nor MRM, Amel, B., Seman, M., \& Mohd Yusoff, M.Y.Z (2017). Religious commitment and its relation to happiness among Muslim students: the educational level as moderator. Journal of Religion and Health, 56(5), 1870-1889. https://doi.org/10.1007/s10943-017-0361-9

3. Afzal, N. (2019). A study on vocabulary-learning problems encountered by BA English majors at the university level of education. Arab World English Journal, 10(3), 81-98. https://doi.org/10.2139/ssrn.3465990

4. Aini R.M., Muslem, A. \& Usman, B. (2020). Lecturers' strategies used in teaching English reading comprehension: a case at a private college in Aceh. Humanities \& Social Sciences Reviews, 8(3), 20-30. https://doi.org/10.18510/hssr.2020.833

5. Al Nakhalah, A.M.M. (2016). Problems and difficulties of speaking that encounter English language students at Al Quds Open University. International Journal of Humanities and Social Science Invention, 5(12), 96-101.

6. Alos S.B., Caranto, L.C., \& David, J.S.T. (2015). Factors affecting the academic performance of the student nurses of BSU. International Journal of Nursing Science, 5(2), 60-65.

7. Amri, A., Aridah, \& Paramalswari, W. (2019). Study habits and English learning achievement of vocational high school students in Samarinda. Advances in Social Science, Education and Humanities Research, 432, 47-51.

8. Bai, B., Shen, B., \& Mei H. (2020). Hong Kong primary students' self-regulated writing strategy use: Influences of gender, writing proficiency, and grade level. Studies in Educational Evaluation, 65, 100839. https://doi.org/10.1016/j.stueduc.2020.100839

9. Bai, J. (2016). Perceived support as a predictor of acculturative stress among international students in the United States. Journal of International Students, 6(1), 93-106.

10. Bakar N.A., Ghani, E.K. \& Majdi, S. (2017). Reasons to high-stress level among undergraduate accounting students: a case study. Saudi Journal of Business and Management Studies, 2(1), 4-11.

11. Carter, B.N. (2016). Association of religious commitment and perceived stress levels in college students. University Honors Program Theses. 183. https://digitalcommons.georgiasouthern.edu/honors-theses/183

12. Dhanalakshmi, K. \& Murty, KVSN (2017). Relationship between study habits and academic stress of B.ed trainees. Scholarly Research Journal for Interdisciplinary Studies, 6(28), 7851-7856.

13. Dian, L. (2018). The use of gadget on students' study habit in English language learning at SMA An-Najiyah Surabaya. A thesis. file:///C:/Users/User/Desktop/GJAT2020/SH\%20and\%20elc/Dian\%20Lutfiani_NIM\%2 0D75213054.pdf

14. Dzulkurnain, M.I., Sunardi, Siswandari, \& Asrowi (2020). Designing English translation towards Indonesian moderate religious based school. Humanities \& Social Sciences Reviews, 8(3), 302-309. https://doi.org/10.18510/hssr.2020.8332 
15. Ennsa A., Eldridge, G.D., Montgomery, C., \& Gonzalez, V.M. (2018). Perceived stress, coping strategies, and emotional intelligence: A cross-sectional study of university students in helping disciplines. Nurse Education Today, 68, 226-231. https://doi.org/10.1016/j.nedt.2018.06.012

16. Fenton-Smith, B., Humphreys, P. \& Walkinshaw, I. (2018). On evaluating the effectiveness of university-wide credit-bearing English language enhancement courses. Journal of English for Academic Purposes. 31, 72-83. https://doi.org/10.1016/j.jeap.2017.12.001

17. Forouhari, S., Teshnizi S.H., Ehrampoush, M.H., Mahmoodabad, S.S.M, Tabei, HFSZ, Nami M., ... Kazemitabaee, M. (2019). Relationship between religious orientation, anxiety, and depression among college students: a systematic review and meta-analysis. Iran Journal of Public Health. 48(1), 43-52. https://doi.org/10.18502/ijph.v48i1.781

18. Horwitz, I.M., Domingue, B.W. \& Harris, K.M. (2020). Not a family matter: The effects of religiosity on academic outcomes based on evidence from siblings. Social Science Research, 88-89 (2020) 102426. https://doi.org/10.1016/j.ssresearch.2020.102426

19. Huh, K. (2015). A comparative study on learning stress and academic self-concept: a small town vs a metropolitan city. Indian Journal of Science and Technology, 8(5), 69-75. https://doi.org/10.17485/ijst/2015/v8iS5/61617

20. Inayah, N., Yusuf, Q. \& Fibula, N. (2020). Exploring undergraduate students' perception toward the use of duo lingo in learning English. Humanities \& Social Sciences Reviews, 8(3), 76-85. https://doi.org/10.18510/hssr.2020.839

21. Jafari, H, Aghaei, A. Khatony, A. (2019). Relationship between study habits and academic achievement in students of medical sciences in Kermanshah-Iran. Advances in Medical Education and Practice, 10, 637-643. https://doi.org/10.2147/AMEP.S208874

22. Khodadady, E. \& Saadi, NS (2015). Religious orientation and English language proficiency. International Journal of Psychology and Behavioral Sciences, 5(1), 35-47.

23. Kim, T.Y. \& Kim, T.K. (2014). A structural model for perceptual learning styles, the ideal L2 self, motivated behaviour, and English proficiency. System, 46, 14-27. https://doi.org/10.1016/j.system.2014.07.007

24. Kumar, A., Ahsan, M., \& Negi, M. (2017). A comparative study of proficiency in English and study habits of government and non-government school students. International Journal of Informative \& Futuristic Research, 5(1), 8746-8770.

25. Luoch, T.O. (2014). The impact of remedial English on the improvement of English proficiency: The case of the United States International University-Africa. Procedia - Social and Behavioral Sciences, 152, 1178-1188. https://doi.org/10.1016/j.sbspro.2014.09.296

26. McGrath, L., Berggren, J. \& Mezek, S. (2016). Reading EAP: Investigating high proficiency L2 university students' strategy use through reading blogs. Journal of English for Academic Purposes, 22, 152-164. https://doi.org/10.1016/j.jeap.2016.03.003

27. Miller, L., Wickramaratne, P., Gameroff, M. J., Sage, M., Tenke, C. E., \& Weissman, M. M. (2012). Religiosity and major depression in adults at high risk: A ten-year prospective study. The American Journal of Psychiatry, 169(1), 89-94. https://doi.org/10.1176/appi.ajp.2011.10121823

28. Mofareh, A. A. (2019). Difficulties facing students in English language conversation. International Research in Higher Education, 4(3), 51-57. https://doi.org/10.5430/irhe.v4n3p51

29. Moosavi, E. G. (2014). Validating a spiritual intelligence scale translated into Persian and exploring its relationship with grade three senior high school students' English achievement (Unpublished master's thesis). Ferdowsi University of Mashhad, Iran.

30. Muliawati, I., Ismail N.M., Lismalinda \& Rizka B. (2020). Test-taking anxiety among EFL university students in TOEFL Test: A case study from the Indonesian context. Humanities \& Social Sciences Reviews, 8(3), 200-208. https://doi.org/10.18510/hssr.2020.8321

31. Ndifon, R.A., Cornelius-Ukpepi, B.U. \& Omoogu, A.C. (2014). The relationship between upper basic pupils' study habits and their academic performance in the English language. British Journal of Education, Society \& Behavioural Science, 4(12), 1676-1686. https://doi.org/10.9734/BJESBS/2014/4025

32. Rabea, R., Almahameed, N.A., Al-Nawafleh, A.H.\& Obaidi, J. (2018). The English language challenges among students of Princess Aisha Bint Al-Hussein College of Nursing \& Health Sciences at Al-Hussein Bin Talal University. Journal of Language Teaching and Research, 9(4), 890-898. https://doi.org/10.17507/jltr.0904.19

33. Ramlee, N., Osman, A., Salahudin, S.N., Yeng, S.K., Ling, S.C. \& Safizal, M. (2016). The influence of religiosity, stress and job attitude towards organisational behavior: evidence from public universities in Malaysia. Procedia Economics and Finance, 35, 563 - 573. https://doi.org/10.1016/S2212-5671(16)00069-1

34. Rao, K.V. \& Reddy, S.V. (2015). Effect of study habits, mental health and academic stress on academic achievement among teacher trainees. Indian Journal of Research, 4(6), 471-473.

35. Sabbah, S. S. (2016). The effect of study habits on English language achievement. Arab World English Journal, 7(4). 238-237. https://doi.org/10.24093/awej/vol7no4.16 
36. Sandilos, L.E., Baroody, A.E., Rimm-Kaufman, S.E. \& Merritt, E.G. (2020). English learners' achievement in mathematics and science: Examining the role of self-efficacy. Journal of School Psychology, 79, 1-15. https://doi.org/10.1016/j.jsp.2020.02.002

37. Seo, E.J., Ahn, J.A., Hayman, L.L. \& Kim, C.J. (2018). The association between perceived stress and quality of life in university students: The parallel mediating role of depressive symptoms and health-promoting behaviours. Asian Nursing Research, 12, 190-196. https://doi.org/10.1016/j.anr.2018.08.001

38. Spivey, C.A., Havrda, D., Stallworth, S., Renfro, C., \& Chisholm-Burns, M.A. (in press). A longitudinal examination of perceived stress and academic performance of first-year student pharmacists, Currents in Pharmacy Teaching and Learning, https://doi.org/10.1016/j.cptl.2020.05.002

39. Sun, \& Wang (2020). College students' writing self-efficacy and writing self-regulated learning strategies in learning English as a foreign language. System, 90, 102221. https://doi.org/10.1016/j.system.2020.102221

40. Taušováa, J., Bendera, M., Dimitrova, R. \& Vijver, F.V.D. (2019). The role of perceived cultural distance, personal growth initiative, language proficiencies, and tridimensional acculturation orientations for psychological adjustment among international students. International Journal of Intercultural Relations, 69, 11-23. https://doi.org/10.1016/j.ijintrel.2018.11.004

41. Tekke, M., Francis, L.J. \& Robbins, M. (2018). Religious affect and personal happiness: A replication among Sunni students in Malaysia. Journal of Muslim Mental Health, 11(2), 3-15. https://doi.org/10.3998/jmmh.10381607.0011.201

42. Teng, L.S., Yuan, R.E. \& Sun, PP (2020). A mixed-method approach to investigating motivational regulation and writing proficiency in English as a foreign language contexts. The system, 88(2020), 102182. Retrieved from https://doi.org/10.1016/j.system.2019.102182

43. Thomas, J., Mutawa, M., Furber, S. W., \& Grey, I. (2016). Religiosity: Reducing depressive symptoms amongst Muslim females in the United Arab Emirates. Middle East Journal of Positive Psychology, 2(1), 9-21.

44. Truong, T.N.N. \& Wang, C. (2019). Understanding Vietnamese college students' self-efficacy beliefs in learning English as a foreign language. System, 84, 123-132. https://doi.org/10.1016/j.system.2019.06.007

45. Umaru U.M., \& Sakariyau, O.B. (2016). The relationship between religiosity and academic performance amongst accounting students. International Journal of Evaluation and Research in Education. 5(2), 165-173. https://doi.org/10.11591/ijere.v5i2.4535

46. Vattoy, K.D. \& Smith, K. (2019). Students' perceptions of teachers' feedback practice in teaching English as a foreign language. Teaching and Teacher Education, 85, 260-268. https://doi.org/10.1016/j.tate.2019.06.024

47. Xing, D. \& Bolden, B. (2019). Exploring oral English learning motivation in Chinese international students with low oral English proficiency. Journal of International Students, 9(3), 834-855. https://doi.org/10.32674/jis.v9i3.749

48. Zabihi, R. (2011). Personality in English language proficiency and achievement. Continental J. Education Research, 4, 1-6. http://www.wiloludjournal.com

49. Zawawi, J.A. (2015). Religious commitment and psychological well-being: forgiveness as a mediator. European Scientific Journal, 11(5), 117-141.

50. Zhang, X., Ardasheva, Y. \& Austin, B.W. (2020). Self-efficacy and English public speaking performance: A mixedmethod approach. English for Specific Purposes, 59, 1-16. https://doi.org/10.1016/j.esp.2020.02.001 